\title{
Growth performance, immune status and organ morphometry in broilers fed Bacillus subtilis-supplemented diet
}

\author{
A. Sikandar ${ }^{1 \#}$, H. Zaneb ${ }^{3 \#}$, M. Younus ${ }^{2}$, S. Masood ${ }^{3}$, A. Aslam ${ }^{4}$, M. Shah ${ }^{6}$ \& H. Rehman ${ }^{5}$ \\ ${ }^{1}$ Department of Basic Sciences, ${ }^{2}$ Department of Pathobiology, Sub-campus, Jhang, University of Veterinary and Animal \\ Sciences (UVAS), Lahore 35200; ${ }^{3}$ Department of Anatomy and Histology, ${ }^{4}$ Department of Pathology, ${ }^{5}$ Department of \\ Physiology, UVAS, Lahore 54000, Pakistan. \\ ${ }^{6}$ Department of Animal Health, University of Agriculture, Peshawar 25000, Pakistan.
}

(Received 3 March 2017; Accepted 28 March 2017; First published online 28 April 2017)

\author{
Copyright resides with the authors in terms of the Creative Commons Attribution 4.0 South African Licence. \\ See: http://creativecommons.org/licenses/by/4.0/za \\ Condition of use: The user may copy, distribute, transmit and adapt the work, but must recognise the authors and the South African \\ Journal of Animal Science.
}

\begin{abstract}
The present research aimed to investigate the effects of Bacillus subtilis (B. subtilis) on performance, immune system, gut, and lymphoid organs' microarchitecture in broilers. A total of 120 day-old broiler chicks were randomly distributed into four groups. The birds were fed a corn-soy-based basal diet (BD) (control) or the same BD supplemented with $10 \%$ zinc bacitracin $(\mathrm{ZnB}), 0.05 \mathrm{~g} / \mathrm{kg}$ or $0.1 \mathrm{~g} / \mathrm{kg}$ of $B$. subtilis (BS). The broilers fed $0.1 \mathrm{~g} / \mathrm{kg}$ of $B$. subtilis had superior mean bodyweight and lower feed conversion ratio compared with the non-supplemented or ZnB-fed groups. The BS-0.1 group registered higher antibody titer against the Newcastle disease (ND) virus. Cell-mediated immune response post Phytohaemagglutinin-P (PHA-P) injection was attained by both BS- 0.1 and BS-0.05 groups. Histomorphological study revealed increased thymus cortical width, and cortex/medulla ratio in BS-0.1 group compared with control. Area of bursal follicles and germinal centres of spleen also improved in BS-0.1 group. Compared to $\mathrm{ZnB}$ and control, higher villus height $(\mathrm{VH})$ and villus crypt ratio of the duodenum and jejunum were recorded on day 21, and higher $\mathrm{VH}$ of duodenum and ileum was noted on day 35 in BS-0.1 and BS-0.05 groups. In conclusion, B. subtilis-type probiotics contributed positively to better growth performance, improved immune system and modulated morphology of lymphoid organs and gut mucosa in broilers.
\end{abstract}

Keywords: Immunity, intestinal mucosa, poultry, probiotics

\#Corresponding authors: hafsa.zaneb@uvas.edu.pk, arbab.sikandar@uvas.edu.pk

\section{Introduction}

Proper digestion, absorption, and conversion of feedstuff into valuable end products are important factors in animal growth performance. Healthy gut development and its mucosal modulations are of substantial importance. The small intestine provides a prime location for digestion and absorption of available nutrients. The important histological component in this portion is the villus (Ragaa \& Korany, 2016). An increase in villus length results in an enlargement of the contact surface with the nutrients and improves absorption (Awad et al., 2009), which may be linked to improved growth performance. Certain environmental and managemental stressful factors may lead to poor growth performance through suppression of the immune system (Schwartzman \& Ruby, 2016). The immune system performs a valuable function in protecting the body. Incompetency of the immune system leads to various infections (Madej et al., 2015). For immune modulation, synthetic antibiotics have been used as feed additives in the poultry industry to control the growth of pathogens and thus act as antibiotic growth promoters (AGP) for birds (Kabploy et al., 2016). Following the ban on the use of dietary antimicrobials in Europe (Lee \& Lillehoj, 2016), products such as probiotics, organic acids and phytobiotics are of great importance in replacing AGPs, and have improved gut health.

Probiotics are orally fed living cultures of microorganisms (yeast and bacteria) that reveal favourable outcomes once consumed. Variable findings have been reported about the effects of probiotic-supplemented diets on growth performance and immune-associated organs of broilers. Probiotics have been found to stimulate gut-associated lymphoid tissues (Haghighi et al., 2006), and are assumed to affect other lymphoid organs through mucosal-associated lymphoid tissue. Probiotics are also active against enteropathogens in several ways, including improved immunity-based elimination, competing for mucosal attachment and crucial nutrients, and producing antimicrobial complexes (Patel et al., 2015). They colonize in the gut and its 
antigenic fragments have the ability to cross the mucosal barrier (Dobson et al., 2012). In lamina propria mucosae, the dendritic cells present these fragments to $T$ and $B$ lymphocytes in the germinal centres of the immune organs (Jiang et al., 2004). Through this process, probiotics modulate immune responses in the animals. Probiotics flourish in the gut of hosts and enhance the growth of intestinal beneficial commensals (Lee et al., 2016), minimizing the destruction triggered by pathogens (Park et al., 2014), supporting the integrity of gut mucosa and maintaining stability and balance of normal microflora (Lei et al., 2015). They are known to improve relative weight of spleen. However, a comparable effect on bursa is controversial (Zhang et al., 2012).

B. subtilis, as spores or direct-fed microbials (DFM) as vegetative cells, is likely to fortify the performance of the immune system by lowering oxygen, releasing proteases and decreasing the $\mathrm{pH}$ of the gut. These changes are brought about through an increase in the population of beneficial intestinal microflora, including Lactobacillus, and may lead to reduced growth of pathogenic bacteria in the gut (Park et al., 2014). Direct-fed microbials are known to decrease the intestinal luminal $\mathrm{pH}$ and maintain the equilibrium, stability and enhancement of other gut microbiota (Lei et al., 2015). It has been suggested that $B$. subtilis should be offered continuously to broilers in feed (Latorre et al., 2014). Based on non-toxigenic and beneficial effects, European Food Safety Authority (EFSA) declared that $B$. subtilis is a safe animal feed additive for veterinary use (EFSA, 2015). B. subtilis is reported to have the ability to improve digestion and promote growth (Tactacan et al., 2013), and food conversion ratio (FCR) (Teo \& Tan 2007; Lei et al., 2015) in host animals. Based on reported advantageous features, the authors hypothesized that $B$. subtilis may be a potential replacement for AGP in broilers. Therefore, the present study reports the effects of $B$. subtilis supplementation on growth performance, cellular and humoral immune responses, relative weight and morphometry of lymphoid organs, and gut mucosal microstructural modulations.

\section{Materials and methods}

The study was executed in an environmentally controlled research shed at the Department of Poultry Production, University of Veterinary and Animal Sciences-Lahore, Pakistan. A total of 120 day-old broiler chicks (Hubbard M77) were reared for 35 days under standard husbandry conditions approved by the Ethical Review Committee for the Use of Laboratory Animals of the University (Notification No. DR/ 257 dated 13 April 2015). The temperature and relative humidity $(\mathrm{RH})$ at the beginning were maintained at $33 \pm 2{ }^{\circ} \mathrm{C}$ and $70 \pm 5 \%$, respectively, and were decreased at around $3^{\circ} \mathrm{C}$ per week until they reached $24 \pm 2{ }^{\circ} \mathrm{C}$, with $\mathrm{RH}$ $65 \pm 5 \%$. Thereafter, the temperature was kept constant for the remaining period of the study. On day 1 , chicks were divided randomly into four groups of 30 chicks in each group (BS-0.1, BS-0.05, ZnB and control) with three replicates $(n=10)$ each. The birds in each group were offered a corn-based basal diet (Table 1) in starter (day 1 to day 21) and grower (day 22 to day 35) phases.

Diet and water were supplied ad libitum throughout the study. The birds in the groups BS-0.1 and BS0.05 were supplemented with B. subtilis QST-713 (Agraquest ${ }^{\circledR}$ Bayer, Davis, Calif, USA) at the rate of 0.1 $\mathrm{g} / \mathrm{kg}$ and $0.05 \mathrm{~g} / \mathrm{kg}\left(2.0 \times 10^{10}\right.$ colony forming unit (CFU)/g) feed, respectively. Group ZnB consisted of $10 \%$ ZbN (Hubei Yuancheng Tech. Develop. Co. Ltd. China), and were given $0.01 \%$ of feed, while the control group served as negative control and were maintained on the basal diet only. On day 1 and day 9 , the chicks were vaccinated with Newcastle disease vaccine (Nobilis ND LaSota, Intervet International B.V. Boxmeer, Holland) via the ocular route and boosted on day 16 and day 23 via drinking water.

The cumulative bodyweight of treated chicks was compared with that of the control group. Average bodyweight (ABW), weekly weight gain (WWG), average feed intake (AFI) and FCR were studied to record growth performance (Kiczorowska et al., 2016).

The humoral response was assessed in terms of determination of antibody titer against NDV and sheep RBCs antigens as described earlier (Sikandar et al., 2017). Briefly, two birds from each treatment replicate (group of $n=6$ ) were randomly selected on day 14 and wing tagged. The selected birds were inoculated with $5 \%$ sheep red blood cells (SRBCs) antigen (sheep blood collected in Alsevier's solution, washed thrice and suspended in phosphate buffered saline) in two parts $(0.5 \mathrm{ml}$ each, intramuscularly in both sides of the breast muscles (Musculus pectoralis) on day 14. Booster dose (similar) was given on day 21. Blood samples were collected on day 21 (after 7 days of primary inoculation) and day 35, and sera separated through centrifugation at $2000 \times \mathrm{g}$ for 10 minutes and stored at $-20{ }^{\circ} \mathrm{C}$ till analysis. The immune responses to NDV and SRBCs were measured using micro-titer haemagglutination inhibition and haemagglutination assays, respectively.

Cell-mediated immune response was evaluated in terms of cutaneous basophilic hypersensitivity test produced by injecting phytohemagglutinin-P (PHA-P) (Sigma-Aldrich, USA) as described by Corrier (1990) with minor modifications. Briefly, two birds from each replicate ( $\mathrm{n}=$ six per group) were selected randomly on day 17 and wing tagged. 
Table 1 Control diet composition and calculated analysis

\begin{tabular}{|c|c|c|}
\hline Ingredient (\%) & Starter phase & Grower phase \\
\hline Corn & 40.15 & 57.57 \\
\hline Rice broken & 15 & --- \\
\hline Soy meal & 11.54 & 9.60 \\
\hline Sunflower meal & 12.00 & 13.00 \\
\hline Canola meal & 9.00 & 5.00 \\
\hline Rapeseed meal & 5.00 & 7.60 \\
\hline Rice polish & --- & 4.00 \\
\hline Guar meal & 1.00 & --- \\
\hline Wheat bran & 1.34 & --- \\
\hline Molasses & 2.00 & --- \\
\hline Sodium bicarbonate & 0.03 & 0.065 \\
\hline Sodium chloride & 0.21 & 0.21 \\
\hline Di-calcium phosphate & 1.33 & 1.49 \\
\hline L-Lysine & 0.30 & 0.35 \\
\hline DL-Methionine & 0.10 & 0.12 \\
\hline Vit-mineral premix ${ }^{*}$ & 1.00 & 1.00 \\
\hline \multicolumn{3}{|l|}{ Nutrient composition } \\
\hline Calculated metabolisable energy (kcal.kg) & 2750 & 2850 \\
\hline Crude protein $(\%)$ & 19.6 & 18.5 \\
\hline Dry matter $(\%)$ & 87 & 88 \\
\hline Crude fibre (\%) & 6.05 & 6.35 \\
\hline Crude fat $(\%)$ & 2.16 & 2.35 \\
\hline Total ash (\%) & 5.77 & 5.40 \\
\hline
\end{tabular}

"Vitamin mineral premix (each kg contained ): ascorbic acid, $26000 \mathrm{IU}$; retinol, 200,000 IU; cholecalciferol, 80,000 IU; tocopherol, $1072 \mathrm{IU}$; thiamine, $11666 \mathrm{IU}$; pyridoxine, $33333 \mathrm{IU}$; menadione, 11,333 IU; riboflavin, 54,000 IU ; niacin, 5,36,000 IU; folic acid, $13600 \mathrm{IU}$; methylcobalamin, $223 \mathrm{IU}$; biotin, $1340 \mathrm{IU} ; \mathrm{Ca}, 195 \mathrm{~g}$; K, $70 \mathrm{~g}$; Na, $18 \mathrm{~g}$; Mg, $6 \mathrm{~g} ; \mathrm{Fe}$, 2,000 mg; Zn, 1,200 mg; Mn, 1,200 mg; Cu, 400 mg; I, 40 mg , Co, 20 mg and Se, 8 mg

The PHA-P solution was prepared in sterile phosphate buffered saline (PBS) and injected $(100 \mu \mathrm{g} / 100$ $\mu \mathrm{l} /$ chicken) intradermally between the third and fourth digits of the right foot. The left foot was injected with $100 \mu \mathrm{l} \mathrm{PBS}$ and served as a control. The swelling of the injection site was evaluated with a pressure sensitive micrometer 24, 48, and 72 hours post injection. Cell-mediated immune response (foot web index) to PHA-P was analysed by subtracting the thickness of the left foot from that of the right foot.

Two chickens from each replicate were randomly selected, weighed and killed on day 21 and day 35 . The small intestine, liver, thymus, spleen, and bursa of Fabricius were removed from the carcass and their relative weights were calculated. The representative samples of the organs were subsequently collected and transported to the laboratory in labelled specimen bottles with $10 \%$ neutral buffered formalin for onward procedure.

Histomorphometry of the thymus was done according to Rooney et al. (2003) and Madej et al. (2015) with minor modifications. The thymic lobules were divided into four sections by two lines crossing each other at right angles in the centre of the medulla. All the lines representing the complete width of the cortex were calculated, and average was expressed as cortical thickness. The area of the medulla was calculated by combining the measurements of the two lines representing the length and width of the medulla. Later, the ratios of cortex to medulla were calculated in three well-oriented lobules per section and the mean values, obtained from three sections per bird, were calculated.

Well-oriented germinal centre areas in the spleen were combined and expressed as a percentage of the total field of view at $10 \times$ (Madej et al., 2015). Later the average values of three sections were determined. 
Slides were stained with haematoxylin and eosin (H\&E). The total number of lymphoid follicles in one microscopic field at $4 \times$ magnification were noted. Length, width and area of five well-oriented bursal follicles were measured (Sikandar et al., 2017) per section (three sections per sample). Later the average value of the three sections was determined. The area of the follicles was measured with this equation: follicular width $x$ follicular length.

Segments of approximately $2-\mathrm{cm}$ length were excised from the duodenum $(10 \mathrm{~cm}$ distal to duodenogizzard junction), jejunum (5 $\mathrm{cm}$ proximal to Meckel's diverticulum), and ileum ( $5 \mathrm{~cm}$ anterior to the ileocaecal junction). Intestinal samples were processed with the paraffin-embedding technique, sectioned (5 $\mu \mathrm{m})$ with a microtome (AMOS Scientific AEM-450, Austria), and stained with H\&E, except for histochemical differentiation of goblet cells, for which the slides were stained with periodic acid-Schiff-alcian blue (Bancroft et al., 2008).

Three sections were collected (one section after every 10 sections) from each intestinal sample. From each section, five well-oriented villi with intact lamina propria were randomly selected for observation. Thus an average of 15 values was calculated for each sample. Finally, the mean values from six chickens were expressed as mean values for one treatment group. Slides were examined under a microscope (Olympus CX 31, Olympus USA) at $4 \times$ magnification and operated with a digitalized live image analysis program (Olympus DP 20, Olympus USA). The histomorphological variables, including villus height (VH), villus width (VW), villus surface area (VSA), crypt depth (CD), and villus height to crypt depth ratio (VH : CD) were measured (Kiczorowska et al., 2016).

Normal distribution of the data was confirmed with the Kolmogorov-Smirnov test and was presented as means \pm SEM. The data were analysed with one-way ANOVA (Statistical Package for Social Sciences, SPSS for Windows, version 20, SPSS Inc., Chicago, IL, USA). Statistical differences among treatment means were determined through Duncan's multiple range tests. In all statistical analyses, $P<0.05$ was considered significant.

\section{Results}

Chickens fed a higher level of probiotic (BS-0.1) performed well compared with ZnB and control (Table 2). In the second week, both $B$. subtilis groups showed higher $(P<0.05)$ ABW, WWG, and lower $(P<0.05)$ FCR compared with ZnB and the non-supplemented group. Better growth performance was recorded in BS0.1 compared with $\mathrm{ZnB}$ and the control group in the third week.

Average bodyweight registered better $(P<0.05)$ in $B$. subtilis-supplemented groups compared with $\mathrm{ZnB}$ and control in the fourth week. Average bodyweight and WWG were higher $(P<0.05)$ in BS-0.1 compared with control and $\mathrm{ZnB}$ and control, respectively, in the fifth week. Feed intake differences during the grower phase were not significant among treatment groups.

On day 21 the responses among the groups were found to be non-significant, while on day 35 the antibody response to Newcastle disease virus (NDV) was affected $(P<0.05)$ by the level of $B$. subtilis. Antibody titer against sheep red blood cells (SRBCs) registered higher $(P<0.05)$ in the supplemented groups. There were no significant differences in the titers between the groups that received different concentrations of probiotics (Table 3).

Lymphoproliferative responses to PHA-P were registered higher $(P<0.05)$ in chickens treated with higher concentration of $B$. subtilis compared with $\mathrm{ZnB}$ and control groups.

On day 35 , liver, spleen and thymus weighed more $(P<0.05)$ in the supplemented groups compared with control (Table 4).

On day 35, the thymus cortical width in BS- 0.1 and the medullary area in BS-0.05 improved $(P$ $<0.05)$ compared with control. Compared with control, the germinal centre area of spleen was increased $(P$ $<0.05)$ in BS-0.1 and BS-0.05 groups on day 35. The results showed enlarged $(P<0.05)$ bursal follicular area on day 21, and bursal follicular length on day 35 in BS-0.1 group compared with ZnB and control. Compared with control, the bursal follicular area was greater in BS-0.1 and BS-0.05 groups on day 35 (Table 6).

On day 21 , in comparison with control and $\mathrm{ZnB}$, the thymus cortical width and cortex/medulla ratio increased $(P<0.05)$ in BS-0.1 group (Table 5).

Starter phase (d 21): Compared with $\mathrm{ZnB}$ and control, the histomorphological study revealed higher $(P<0.05) \mathrm{VH}, \mathrm{VSA}$ and $\mathrm{VH}: \mathrm{CD}$ of duodenum and jejunum in both the $B$. subtilis-supplemented groups and $\mathrm{VH}$ and VSA of ileum in BS-0.1. Variation in the VW and CD was non-significant among treatment groups in all three segments except in the duodenum on day 21 , in which the CD was found to be lower $(P<0.05)$ in ZnB compared with all other groups (Table 7).

Grower phase (day 35): VH and VSA in duodenum and ileum increased $(P<0.05)$ in both the $B$. subtilis-treated groups compared with $\mathrm{ZnB}$ and groups (Table 8). 
Table 2 Weekly growth performance results of broilers

\begin{tabular}{|c|c|c|c|c|c|c|}
\hline \multirow{2}{*}{ Age } & \multirow{2}{*}{ Parameter } & \multicolumn{5}{|c|}{ Treatments } \\
\hline & & BS-0.1 & BS-0.05 & $\mathrm{ZnB}$ & Control & P-value \\
\hline \multirow{5}{*}{$\begin{array}{l}\text { 1st } \\
\text { week }\end{array}$} & Avg. bodyweight (g) & $155.43 \pm 1.02$ & $148.17 \pm 2.99$ & $151.40 \pm 1.31$ & $152.03 \pm 1.13$ & .114 \\
\hline & Weekly weight gain (g) & $114.43 \pm 1.02$ & $107.17 \pm 2.99$ & $110.40 \pm 1.31$ & $111.03 \pm 1.13$ & .114 \\
\hline & Avg. feed intake (g) & $129.20 \pm 3.64$ & $126.37 \pm 0.30$ & $127.27 \pm 1.19$ & $134.10 \pm 5.06$ & .119 \\
\hline & FCR & $1.13 \pm 0.02$ & $1.18 \pm 0.09$ & $1.15 \pm 0.03$ & $1.20 \pm 0.02$ & .090 \\
\hline & Avg. bodyweight (g) & $432.93^{\mathrm{a}} \pm 2.94$ & $430.63^{a} \pm 3.94$ & $412.37^{b} \pm 2.02$ & $410.43^{b} \pm 3.81$ & .002 \\
\hline \multirow{3}{*}{$\begin{array}{l}\text { 2nd } \\
\text { week }\end{array}$} & Weekly weight gain (g) & $277.50^{a} \pm 2.14$ & $282.46^{a} \pm 0.95$ & $260.96^{b} \pm 0.84$ & $258.40^{\mathrm{b}} \pm 2.91$ & .000 \\
\hline & Avg. feed intake (g) & $346.17 \pm 0.27$ & $346.50 \pm 1.42$ & $348.70 \pm 1.01$ & $350.23 \pm 0.98$ & .065 \\
\hline & FCR & $1.25^{\mathrm{b}} \pm 0.01$ & $1.23^{b} \pm 0.01$ & $1.34^{a} \pm 0.01$ & $1.36^{a} \pm 0.02$ & .000 \\
\hline \multirow{5}{*}{$\begin{array}{l}\text { 3rd } \\
\text { week }\end{array}$} & Avg. bodyweight (g) & $786.67^{\mathrm{a}} \pm 1.45$ & $760.33^{\mathrm{ab}} \pm 16.91$ & $735.50^{\mathrm{bc}} \pm 3.62$ & $729.00^{c} \pm 4.04$ & .007 \\
\hline & Weekly weight gain (g) & $353.73 \pm 1.51$ & $329.70 \pm 17.28$ & $323.13 \pm 5.21$ & $318.56 \pm 7.71$ & .131 \\
\hline & Avg. feed intake (g) & $512.53^{\mathrm{b}} \pm 1.58$ & $518.40^{\mathrm{a}} \pm 0.31$ & $513.93^{\mathrm{a}} \pm 1.19$ & $523.57^{\mathrm{a}} \pm 5.06$ & .076 \\
\hline & FCR & $1.45^{\mathrm{b}} \pm 0.01$ & $1.59^{\mathrm{a}} \pm 0.09$ & $1.58^{\mathrm{a}} \pm 0.03$ & $1.64^{\mathrm{a}} \pm 0.02$ & .091 \\
\hline & Avg. bodyweight (g) & $1212.83^{\mathrm{a}} \pm 1.57$ & $1192.75^{\mathrm{a}} \pm 4.34$ & $1138.20^{b} \pm 6.55$ & $1039.21^{\mathrm{C}} \pm 10.43$ & .000 \\
\hline \multirow{3}{*}{$\begin{array}{l}\text { 4th } \\
\text { week }\end{array}$} & Weekly weight gain (g) & $426.17^{\mathrm{a}} \pm 0.36$ & $432.42^{\mathrm{a}} \pm 12.83$ & $402.71^{a} \pm 8.11$ & $310.21^{b} \pm 10.78$ & .000 \\
\hline & Avg. feed intake (g) & $745.92 \pm 2.75$ & $738.29 \pm 3.32$ & $741.17 \pm 6.12$ & $733.62 \pm 3.95$ & .291 \\
\hline & FCR & $1.75^{\mathrm{b}} \pm 0.01$ & $1.71^{b} \pm 0.06$ & $1.84^{b} \pm 0.02$ & $2.37^{\mathrm{a}} \pm 0.09$ & .000 \\
\hline \multirow{4}{*}{$\begin{array}{l}5 \text { th } \\
\text { week }\end{array}$} & Avg. bodyweight (g) & $1782.46^{a} \pm 7.38$ & $1701.42^{b} \pm 4.08$ & $1672.21^{b} \pm 14.36$ & $1485.88^{c} \pm 19.83$ & .000 \\
\hline & Weekly weight gain (g) & $569.63^{\mathrm{a}} \pm 8.26$ & $508.67 \pm 3.91^{\mathrm{b}}$ & $534.00^{\mathrm{ab}} \pm 11.38$ & $446.67^{c} \pm 28.81$ & .004 \\
\hline & Avg. feed intake $(\mathrm{g})$ & $1133.92 \pm 29.58$ & $1053.54 \pm 2.92$ & $1062.38 \pm 2.67$ & $1039.46 \pm 4.78$ & .076 \\
\hline & FCR & $1.94 \pm 0.07$ & $2.07 \pm 0.02$ & $1.99 \pm 0.04$ & $2.35 \pm 0.17$ & .063 \\
\hline
\end{tabular}

${ }^{a b c}$ Means within a row marked with different superscripts were significantly different $(P<0.05)$

Values represent mean \pm SEM

BS-0.1, BS-0.05 (0.1 g or $0.05 \mathrm{~g}$ B. subtilis per $\mathrm{kg}$ ); ZnB: $10 \%$ zinc bacitracin, $0.01 \%$ of feed; FCR: feed conversion ratio

Table 3 Humoral immune responses in broilers during starter and finisher phases

\begin{tabular}{|c|c|c|c|c|}
\hline \multirow{3}{*}{ Treatments } & \multicolumn{4}{|c|}{ Antibody titre $\left(\log _{2}\right)$ on various days } \\
\hline & \multicolumn{2}{|c|}{ NDV } & \multicolumn{2}{|c|}{ SRBC } \\
\hline & Day 21 & Day 35 & Day 21 & Day 35 \\
\hline BS-0.1 & $2.21 \pm 0.06$ & $2.27^{\mathrm{a}} \pm 0.05$ & $5.50 \pm 0.22$ & $7.33^{a} \pm 0.42$ \\
\hline BS-0.05 & $2.26 \pm 0.09$ & $2.21^{\mathrm{ab}} \pm 0.06$ & $5.50 \pm 0.22$ & $7.83^{a} \pm 0.30$ \\
\hline $\mathrm{ZnB}$ & $2.09 \pm 0.12$ & $1.98^{\mathrm{b}} \pm 0.09$ & $5.66 \pm 0.33$ & $7.16^{a} \pm 0.30$ \\
\hline Control & $1.98 \pm 0.11$ & $1.98^{b} \pm 0.09$ & $5.16 \pm 0.30$ & $6.00^{b} \pm 0.36$ \\
\hline P-value & 0.332 & 0.035 & 0.638 & 0.011 \\
\hline
\end{tabular}

\footnotetext{
${ }^{\mathrm{ab}}$ Means within a column marked with different superscripts were significantly different $(P<0.05)$

Values represent mean \pm SEM.

NDV: Newcastle disease virus; SRBC: sheep red blood cells; BS-0.1, BS-0.05:(0.1 g or $0.05 \mathrm{~g}$ B. subtilis per kg; ZnB

$(10 \%$ zinc bacitracin, $0.01 \%$ of feed $)$
} 
Table 4 Relative weight ${ }^{1}$ of immune related organs in broilers

\begin{tabular}{|c|c|c|c|c|}
\hline \multirow{2}{*}{ Treatments } & \multicolumn{4}{|c|}{ Relative organs weight ${ }^{1}$ at day-35 } \\
\hline & Liver & Spleen & Thymus & Bursa \\
\hline BS-0.1 & $1.8770^{\mathrm{a}} \pm 0.07$ & $0.1729^{a} \pm 0.01$ & $0.4014^{a} \pm 0.01$ & $0.181 \pm 0.03$ \\
\hline BS-0.05 & $1.6189^{\mathrm{a}} \pm 0.09$ & $0.1395^{a} \pm 0.01$ & $0.3804^{\mathrm{a}} \pm 0.00$ & $0.165 \pm 0.02$ \\
\hline ZnB & $1.5971^{a} \pm 0.11$ & $0.1435^{a} \pm 0.02$ & $0.3857^{\mathrm{a}} \pm 0.00$ & $0.162 \pm 0.02$ \\
\hline Control & $1.5753^{\mathrm{b}} \pm 0.05$ & $0.0960^{\mathrm{b}} \pm 0.01$ & $0.3184^{b} \pm 0.01$ & $0.116 \pm 0.02$ \\
\hline P-value & 0.015 & 0.008 & 0.000 & 0.277 \\
\hline
\end{tabular}

Table 5 Results of morphology of immune organs in broilers on day 21

\begin{tabular}{|c|c|c|c|c|c|c|}
\hline \multirow{2}{*}{ Organs } & \multirow{2}{*}{ Parameters } & \multicolumn{5}{|c|}{ Treatments } \\
\hline & & BS-0.1 & BS-0.05 & PC & NC & $\begin{array}{c}P \text { - } \\
\text { value }\end{array}$ \\
\hline \multirow{3}{*}{ Thymus } & Thymic cortex $(\mu \mathrm{m})$ & $363.22^{\mathrm{a}} \pm 32.59$ & $324.67^{\mathrm{ab}} \pm 17.59$ & $295.83^{b} \pm 12.24$ & $288.17^{\mathrm{b}} \pm 11.49$ & .066 \\
\hline & $\begin{array}{c}\text { Thymic medulla } \\
(\mu \mathrm{m})^{2}\end{array}$ & $437.50 \pm 42.88$ & $522.67 \pm 10.14$ & $523.67 \pm 26.29$ & $494.00 \pm 25.26$ & .146 \\
\hline & Cortex: medulla & $0.8562^{\mathrm{a}} \pm .10$ & $0.6237^{\mathrm{b}} \pm .04$ & $0.5741^{\mathrm{b}} \pm .04$ & $0.5912^{b} \pm .04$ & .016 \\
\hline Spleen & $\begin{array}{l}\text { Germinal centre/ } \\
\text { field area (\%) }\end{array}$ & $0.7326 \pm 0.05$ & $0.6473 \pm 0.09$ & $0.6465 \pm 0.04$ & $0.6449 \pm 0.03$ & .700 \\
\hline \multirow{4}{*}{ Bursa } & $\begin{array}{l}\text { Bursal follicular } \\
\text { length }(\mu \mathrm{m})\end{array}$ & $563.17 \pm 31.26$ & $542.50 \pm 19.2$ & $485.50 \pm 29.20$ & $468.67 \pm 44.10$ & .152 \\
\hline & $\begin{array}{l}\text { Bursal follicular } \\
\text { width }(\mu \mathrm{m})\end{array}$ & $188.50 \pm 22.60$ & $189.67 \pm 15.59$ & $155.50 \pm 8.29$ & $142.67 \pm 8.75$ & .089 \\
\hline & $\begin{array}{l}\text { Bursal follicular } \\
\text { area }(\mu \mathrm{m})^{2}\end{array}$ & $107182.8^{a} \pm 17112.9$ & $102024.3^{\mathrm{ab}} \pm 6748$ & $75004.3^{\mathrm{bc}} \pm 5042.7$ & $66691^{\mathrm{c}} \pm 7330.1$ & .027 \\
\hline & $\begin{array}{l}\text { Bursal follicular } \\
\text { number }\end{array}$ & $10.17 \pm 0.98$ & $10.50 \pm 0.43$ & $8.83 \pm 0.48$ & $8.67 \pm 0.71$ & .175 \\
\hline
\end{tabular}

Means within a row marked with different superscripts were significantly different $(P<0.05)$.

Values represent the mean \pm SEM.

BS-0.1, BS-0.05 (0.1 g or $0.05 \mathrm{~g}$ B. subtilis per $\mathrm{kg}$ ); ZnB ( $10 \%$ zinc bacitracin, $0.01 \%$ of feed).

\section{Discussion}

Replacing antibiotics with feed additives is no longer an option but a necessity. B. subtilis, a probiotic, has been reported to have the potential to promote gut health when supplemented in broiler feed. The current study was designed to compare the effects of probiotic and antibiotic on growth performance, immune status, and histomorphological modulations in the immune organs and small intestinal mucosa.

Dietary fed probiotics, including $B$. subtilis strains, have been reported to be potential growth promoters and immune modulator agents (Lee et al., 2015), but little is known about the effect of the $B$. subtilis QST-713 strain. In the current study, the chickens fed with high-concentrate probiotic gained more weight during the starter and finisher phases (Table 2) than the $\mathrm{ZnB}$ and control groups. This may be attributed to the nutritional benefits of $B$. subtilis (Lei et al., 2015), which fortified growth. Feed intake was non-significant among treatment groups and, overall, better FCR was observed in the Bacillus-supplemented groups. These findings are similar to the observations of Al-Fataftah and Abdelqader (2014), which explained that animals performed well after being fed Bacillus-type probiotics. Various kinds of genes related to feed digestion in the broiler gut are regulated by DFM (Lee et al., 2015), such as those for lipase (CEL), chymotrypsin (CTRC), carboxypeptidase (CPA1), amylase (AMY2A), and pancreatic lipase (PNLIP). Compared with lower concentrations, the high concentration of $B$. subtilis in diet may enhance the release of 
various digestive enzymes, which results in effective digestion and absorption of useful nutrients (Al-Fataftah \& Abdelqader, 2014). In the light of the current observations, it may be assumed that probiotics are beneficial when used in high concentrations in the feed. These assumptions are strengthened by the statements of EFSA (2015), which reported that $B$. subtilis can express more valuable effects if used in a minimum concentration of $1 \times 10^{8} \mathrm{CFU} / \mathrm{kg}$ of feed.

Table 6 Results of morphology of immune organs in broilers on day 35

\begin{tabular}{|c|c|c|c|c|c|c|}
\hline \multirow{2}{*}{ Organs } & \multirow{2}{*}{ Parameter } & \multicolumn{5}{|c|}{ Treatments } \\
\hline & & BS-0.1 & BS-0.05 & ZnB & NC & P-value \\
\hline \multirow{3}{*}{ Thymus } & Thymic cortex $(\mu \mathrm{m})$ & $311.52^{\mathrm{a}} \pm 4.09$ & $282.50^{\mathrm{ab}} \pm 16.86$ & $257.67^{\mathrm{bc}} \pm 12.96$ & $234.83^{\mathrm{C}} \pm 17.91$ & .006 \\
\hline & Thymic medulla $(\mu \mathrm{m})^{2}$ & $433.50^{\mathrm{ab}} \pm 25.49$ & $463.50^{\mathrm{a}} \pm 35.59$ & $404.67^{\mathrm{ab}} \pm 27.33$ & $364.50^{b} \pm 14.18$ & .090 \\
\hline & Cortex: medulla & $0.7326 \pm .05$ & $0.6465 \pm .09$ & $0.6473 \pm .04$ & $0.6449 \pm .04$ & .700 \\
\hline Spleen & $\begin{array}{l}\text { Germinal centre/field } \\
\text { area }(\%)\end{array}$ & $0.8904^{\mathrm{a}} \pm 0.13$ & $0.8722^{\mathrm{a}} \pm 0.07$ & $0.7550^{\mathrm{ab}} \pm 0.05$ & $0.5329^{b} \pm 0.09$ & .045 \\
\hline \multirow{4}{*}{ Bursa } & Bursal follicular length $(\mu \mathrm{m})$ & $451.83^{\mathrm{a}} \pm 29.25$ & $422.83^{\mathrm{ab}} \pm 11.35$ & $373.67^{b} \pm 21.53$ & $373.17^{b} \pm 17.56$ & .035 \\
\hline & Bursal follicular width $(\mu \mathrm{m})$ & $148.00 \pm 10.99$ & $155.50 \pm 8.56$ & $134.50 \pm 18.24$ & $104.67 \pm 9.97$ & .227 \\
\hline & Bursal follicular area $(\mu \mathrm{m})^{2}$ & $66356.3^{\mathrm{a}} \pm 4926.2$ & $65792.8^{\mathrm{a}} \pm 4116.0$ & $50285.0^{\mathrm{ab}} \pm 7721.8$ & $38022.5^{\mathrm{b}} \pm 3932.6$ & .019 \\
\hline & Bursal follicular number & $9.00 \pm 0.58$ & $8.83 \pm 0.98$ & $7.50 \pm 0.67$ & $7.00 \pm 0.58$ & .167 \\
\hline
\end{tabular}

${ }^{\mathrm{ab}}$ Means within a row marked with different superscripts were significantly different $(P<0.05)$.

Values represent Mean \pm SEM.

BS-0.1, BS-0.05 (0.1 g or $0.05 \mathrm{~g}$ B. subtilis per $\mathrm{kg}$ ); ZnB ( $10 \%$ zinc bacitracin, $0.01 \%$ of feed).

Table 7 Results of morphology of small intestine in broilers on day 21

\begin{tabular}{|c|c|c|c|c|c|c|}
\hline \multirow{2}{*}{$\begin{array}{l}\text { Intestinal } \\
\text { segments }\end{array}$} & \multirow{2}{*}{ Parameters } & \multicolumn{5}{|c|}{ Treatments } \\
\hline & & BS-0.1 & BS-0.05 & $\mathrm{ZnB}$ & Control & P-value \\
\hline \multirow{5}{*}{ Duodenum } & Villus height $(\mu \mathrm{m})$ & $1529.45^{a} \pm 20.03$ & $1499.63^{a} \pm 29.69$ & $1019.86^{\mathrm{b}} \pm 17.35$ & $1033.25^{b} \pm 14.83$ & .000 \\
\hline & Villus width $(\mu \mathrm{m})$ & $151.60 \pm 7.73$ & $143.20 \pm 9.53$ & $148.76 \pm 17.27$ & $129.62 \pm 6.49$ & .521 \\
\hline & $\begin{array}{l}\text { Villus surface area } \\
\qquad(\mu \mathrm{m})^{2}\end{array}$ & $665683^{a} \pm 35889$ & $626945^{\mathrm{a}} \pm 45697$ & $453289^{b} \pm 54907$ & $387545^{b} \pm 19406$ & .000 \\
\hline & Crypt depth $(\mu \mathrm{m})$ & $141.50^{a} \pm 8.29$ & $138.66^{a} \pm 4.26$ & $118.30^{b} \pm 2.52$ & $126.58^{\mathrm{ab}} \pm 4.19$ & .018 \\
\hline & $\mathrm{VH}: \mathrm{CD}$ & $10.97^{\mathrm{a}} \pm 0.59$ & $10.89^{\mathrm{a}} \pm 0.51$ & $8.63^{\mathrm{b}} \pm 0.18$ & $8.21^{b} \pm 0.33$ & .000 \\
\hline \multirow{5}{*}{ Jejunum } & Villus height $(\mu \mathrm{m})$ & $916.50^{\mathrm{a}} \pm 14.28$ & $899.00^{\mathrm{a}} \pm 18.73$ & $686.00^{b} \pm 10.77$ & $658.00^{b} \pm 17.64$ & .000 \\
\hline & Villus width $(\mu \mathrm{m})$ & $108.06 \pm 3.87$ & $107.91 \pm 4.97$ & $107.17 \pm 4.29$ & $107.53 \pm 1.94$ & .998 \\
\hline & $\begin{array}{l}\text { Villus surface area } \\
\qquad(\mu \mathrm{m})^{2}\end{array}$ & $308927^{\mathrm{a}} \pm 14424$ & $303703^{\mathrm{a}} \pm 10659$ & $232377^{b} \pm 7662$ & $221756^{\mathrm{b}} \pm 3749$ & .000 \\
\hline & Crypt depth $(\mu \mathrm{m})$ & $114.80 \pm 4.57$ & $113.21 \pm 5.57$ & $104.07 \pm 6.36$ & $106.68 \pm 2.75$ & .390 \\
\hline & $\mathrm{VH}: \mathrm{CD}$ & $8.06^{a} \pm 0.42$ & $8.02^{a} \pm 0.63$ & $6.76^{\mathrm{b}} \pm 0.57$ & $6.19^{b} \pm 0.23$ & .009 \\
\hline \multirow{5}{*}{ Ileum } & Villus height $(\mu \mathrm{m})$ & $487.01^{a} \pm 20.21$ & $469.73^{\mathrm{ab}} \pm 16.41$ & $422.03^{b} \pm 16.43$ & $417.20^{b} \pm 17.87$ & .026 \\
\hline & Villus width $(\mu \mathrm{m})$ & $106.33 \pm 2.97$ & $105.17 \pm 3.17$ & $102.48 \pm 2.19$ & $99.82 \pm 3.33$ & .425 \\
\hline & $\begin{array}{l}\text { Villus surface area } \\
\qquad(\mu \mathrm{m})^{2}\end{array}$ & $163063^{a} \pm 9559$ & $155360^{\mathrm{ab}} \pm 8318$ & $137514^{b} \pm 5554$ & $131227^{b} \pm 9138$ & .038 \\
\hline & Crypt depth $(\mu \mathrm{m})$ & $116.06 \pm 4.20$ & $117.90 \pm 3.99$ & $109.88 \pm 3.75$ & $110.93 \pm 2.99$ & .383 \\
\hline & $\mathrm{VH}: \mathrm{CD}$ & $4.21 \pm 0.18$ & $3.99 \pm 0.15$ & $3.85 \pm 0.17$ & $3.79 \pm 0.26$ & .454 \\
\hline
\end{tabular}

\footnotetext{
${ }^{\text {ab }}$ Means within a row marked with different superscripts were significantly different $(P<0.05)$ SEM obtained in pool, Values represent mean \pm SEM

BS-0.1, BS-0.05 (0.1 g or $0.05 \mathrm{~g}$ B. subtilis per $\mathrm{kg}$ ); ZnB (10\% zinc bacitracin, $0.01 \%$ of feed); VH : CD, villus height and crypt depth ratio
} 
Table 8 Results of morphology of small intestine in broilers on day 35

\begin{tabular}{|c|c|c|c|c|c|c|}
\hline \multirow{2}{*}{$\begin{array}{l}\text { Intestinal } \\
\text { segments }\end{array}$} & \multirow{2}{*}{ Parameters } & \multicolumn{5}{|c|}{ Treatments } \\
\hline & & BS-0.1 & BS-0.05 & ZnB & Control & $\begin{array}{c}\text { P- } \\
\text { value }\end{array}$ \\
\hline \multirow{5}{*}{ Duodenum } & Villus height $(\mu \mathrm{m})$ & $1462.78^{a} \pm 47.61$ & $1399.63^{a} \pm 30.63$ & $1116.70^{b} \pm 27.02$ & $1102.41^{b} \pm 44.50$ & .000 \\
\hline & Villus width $(\mu \mathrm{m})$ & $150.43 \pm 7.71$ & $153.20 \pm 9.53$ & $151.60 \pm 19.34$ & $129.62 \pm 6.49$ & .572 \\
\hline & $\begin{array}{l}\text { Villus surface } \\
\text { area }(\mu \mathrm{m})^{2}\end{array}$ & $693732^{a} \pm 51137$ & $674774^{\mathrm{ab}} \pm 48161$ & $531710^{\mathrm{bc}} \pm 68505$ & $449158^{c d} \pm 31243$ & .008 \\
\hline & Crypt depth $(\mu \mathrm{m})$ & $129.58 \pm 4.09$ & $124.66 \pm 2.78$ & $113.30 \pm 2.20$ & $119.85 \pm 6.92$ & .089 \\
\hline & $\mathrm{VH}: \mathrm{CD}$ & $11.32^{\mathrm{a}} \pm 0.42$ & $11.25^{\mathrm{a}} \pm 0.28$ & $9.87^{b} \pm 0.25$ & $9.34^{b} \pm 0.65$ & .007 \\
\hline \multirow{5}{*}{ Jejunum } & Villus height $(\mu \mathrm{m})$ & $750.06 \pm 56.43$ & $728.86 \pm 36.88$ & $643.30 \pm 30.77$ & $685.15 \pm 14.62$ & .226 \\
\hline & Villus width $(\mu \mathrm{m})$ & $117.95 \pm 7.81$ & $113.22 \pm 7.38$ & $112.85 \pm 4.64$ & $110.70 \pm 5.69$ & .881 \\
\hline & $\begin{array}{l}\text { Villus surface } \\
\text { area }(\mu \mathrm{m})^{2}\end{array}$ & $283330 \pm 38433$ & $261442 \pm 28099$ & $227965 \pm 14627$ & $238531 \pm 14393$ & .456 \\
\hline & Crypt depth $(\mu \mathrm{m})$ & $122.88 \pm 7.48$ & $123.03 \pm 6.04$ & $121.79 \pm 5.02$ & $124.76 \pm 9.62$ & .993 \\
\hline & VH : CD & $6.26 \pm 0.66$ & $5.89 \pm 0.36$ & $5.37 \pm 0.46$ & $5.75 \pm 0.52$ & .669 \\
\hline \multirow{5}{*}{ Ileum } & Villus height $(\mu \mathrm{m})$ & $526.33^{a} \pm 12.98$ & $520.18^{a} \pm 8.31$ & $436.17^{b} \pm 8.09$ & $429.44^{b} \pm 15.31$ & .000 \\
\hline & Villus width $(\mu \mathrm{m})$ & $112.01 \pm 6.40$ & $110.36 \pm 7.62$ & $104.85 \pm 7.14$ & $102.39 \pm 5.18$ & .710 \\
\hline & $\begin{array}{l}\text { Villus surface area } \\
(\mu \mathrm{m})^{2}\end{array}$ & $185479^{\mathrm{a}} \pm 12430$ & $181053^{\mathrm{a}} \pm 14635$ & $143299^{b} \pm 9225$ & $1382941^{b} \pm 6930$ & .017 \\
\hline & Crypt depth $(\mu \mathrm{m})$ & $101.71 \pm 3.13$ & $100.05 \pm 3.82$ & $105.36 \pm 3.18$ & $106.45 \pm 1.54$ & .507 \\
\hline & $\mathrm{VH}: \mathrm{CD}$ & $5.21^{a} \pm 0.24$ & $5.24^{a} \pm 0.25$ & $4.15^{b} \pm 0.14$ & $4.04^{b} \pm 0.11$ & .001 \\
\hline
\end{tabular}

\footnotetext{
${ }^{\mathrm{abc}}$ Means within a row marked with different superscripts were significantly different $(P<0.05)$

SEM obtained in pool

Values represent mean \pm SEM

BS-0.1, BS-0.05 (0.1 g or $0.05 \mathrm{~g}$ B. subtilis per $\mathrm{kg}$ ); ZnB (10\% zinc bacitracin, $0.01 \%$ of feed); VH : CD, villus height and crypt depth ratio
}

In vivo evaluation of immune response to NDV and SRBCs was carried out by quantifying serum antibody titers in chickens. Vaccinations against infectious diseases, including ND, are used worldwide as prophylactic measures in poultry. SRBCs act as nonpathogenic thymus-dependent immunogens (Kundu et al., 1999). Probiotics have been found to modulate immunity by mediating the immune response of $\operatorname{lgM}$ serotype against SRBCs in birds (Haghighi et al., 2006). Molnar et al. (2011) reported higher antibody titer against NDV in birds maintained on feed supplemented with B. subtilis (CHCC3810-DSM17299). It is expected that birds could survive the ND challenge when they show relatively greater titers. The authors observed higher $(P<0.05)$ antibody titers against NDV in the BS- 0.1 group and in the supplemented groups against SRBCs on day 35 compared with control (Table 3), which reflects enhanced and ongoing plasma cell involvement in the production of antibodies till at least 18 days' post last antigenic exposure.

Lymphoproliferative immune response evaluation is a non lethal simple in vivo test in which the T cell mitogenic PHA-P is administered intradermally to assess the magnitude of cell-mediated immunity in the form of expanse of thickness and swelling (Corrier, 1990). The authors found that probiotic improved the cellmediated immune response at 24, 48 and 72 hours post PHA-P injection compared with the $\mathrm{ZnB}$ and control groups (Figure 1). In light of these results it is indicated that birds maintained on diets supplemented with 0.1 $\mathrm{g} / \mathrm{kg}\left(2.0 \times 10^{10} \mathrm{CFU} / \mathrm{g}\right)$ B. subtilis developed relatively strong humoral and cellular responses. 


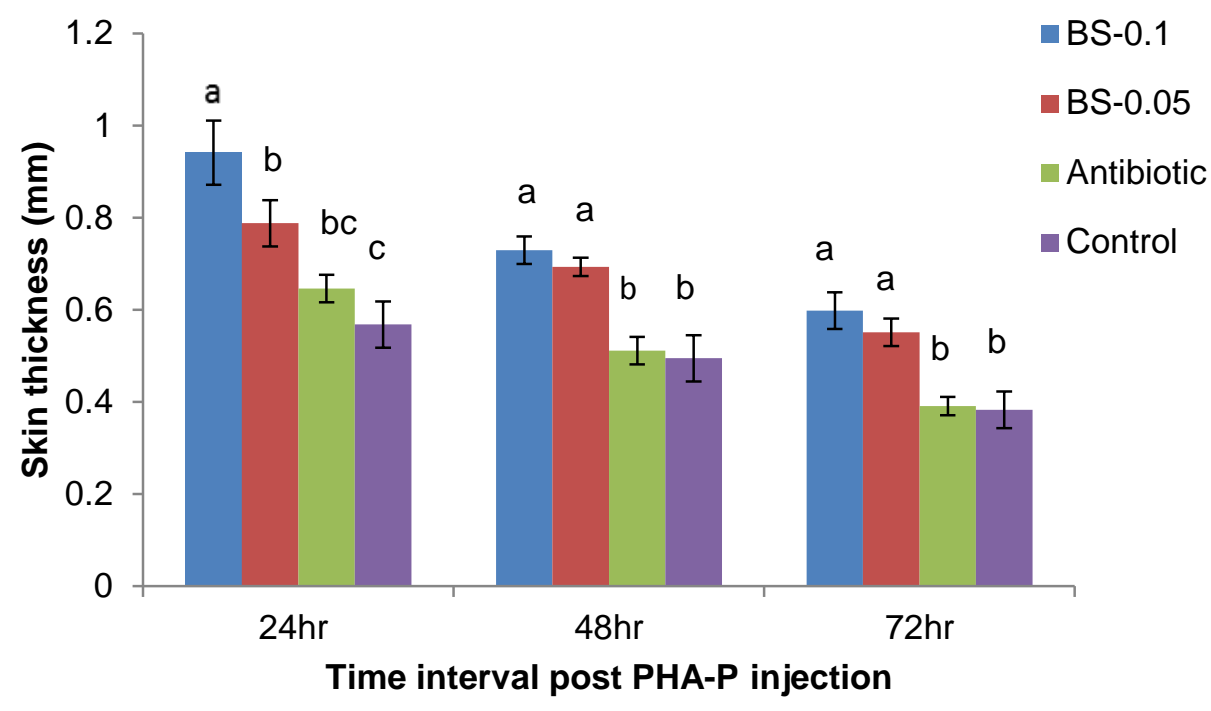

Skin thickness at 24, 48 and 72 hours post PHA-P intradermal injections in chickens. Bars in the graph marked with different letters at a particular time interval were significantly $(P<0.05)$ different

Figure 1 Effect of $B$. subtilis and zinc bacitracin on cell-mediated immune response against Phytohemagllutinin- $P$ in broilers

Spleen, thymus, and bursa are the hub of immune cells where production and orientation of the cells occurs more efficiently in healthy animals than in immune-compromised ones. In disease-free animals, an increase in weight of immune organs correlates with enhanced proliferation of immune cells, which represents better immunity of the body (Teo \& Tan, 2007). Liver participates in metabolization and contributes to immunity by synthesizing accessory proteins. The authors noted the higher $(P<0.05)$ relative weights of lymphoid organs in the supplemented groups (Table 4), which could be the consequence of amplified $B$ and $T$ lymphocytes, as observed in high antibody titration and acidic natured goblet cells in the ileal mucosa. Comparable with these findings, Awad et al. (2009) reported higher $(P<0.05)$ relative weight of liver and spleen and absolute weight of thymus on day 35 after feeding a Lactobacillus-type of probiotic. After in ovo inoculation of prebiotics and synbiotics, Madej et al. (2015) reported a trend of increased thymus relative weight on days 1,7 , and 35 . Teo \& Tan, 2007) found improved $(P<0.05)$ indices of bursa of Fabricius in chickens fed probiotics. Similarly, in the current study the bursa weighed numerically higher in Bacillus-supplemented groups on day 35.

Various compartments in each lymphoid organ specify and maintain immune-related functions. The components were evaluated individually in the current study.

The histomorphological variations in cortex and medulla have a link with immune function. The larger cortex width seen in the current study (Tables 5 and 6) may be a sign of the rapid maturation rate of thymocytes, specifically T lymphocyte (Rooney et al., 2003). A significant increase in the cortex/medullary ratio observed in BS- 0.1 on day21 indicated that hyperplastic proliferation and maturation of T cells (CD4+ or CD8+) occurred extensively in the cortex. These cells later migrate to the medulla and approach the secondary lymphatic organs via blood circulation. Histologically, it is obvious that the increased cortex : medulla ratio was because of thickening of the cortex, without any significant change in the widening of the medulla. Slawinska et al. (2014) reported that in ovo synbiotic-treated chickens established superior thymocyte densities in the cortex of the thymus compared with control on days 21 and 42 . Madej et al. (2015) also reported that in ovo-delivered pre and symbiotic results in the higher cortex/medulla ratio on days 1,7 , and 35 , while these were lower $(P<0.05)$ on day 21 than in the control.

The germinal centre area is one of the important histological features in the spleen. Coupled with an increase in its relative weight (Table 4) in the supplemented groups, the authors noted increased $(P<0.05)$ germinal centre area in spleen on day 35 (Table 6), which is similar to the findings of Madej et al. (2015) in symbiotic-treated chickens. It is assumed that $B$. subtilis had a stimulatory effect on B cells in the spleen, which might have potentiated the immune system by immunoglobulin synthesis. Similarly, Slawinska et al. (2014) reported that certain synbiotics may up-regulate the gene expression of IL-4 and IL-6 in the parenchyma of spleen, which later stimulates B cells. 
The bursa is the main organ of the immune system in avian species. The dimensional increase $(P$ $<0.05$ ) of the follicular area in BS-0.1 group (Table 5) indicates the immunomodulatory properties of $B$. subtilis. Similarly, Molnar et al. (2011) reported increased lymphoid follicular area in birds offered $B$. subtilis. The histomorphological improvements in various aspects of immune-related organs in chickens fed $B$. subtilis indicates that these probiotics may modulate systemic immune systems in addition to local mucosal immunity.

Most poultry producers and researchers agree that feed supplementation with probiotics from an early age helps to maintain mucosal integrity, promotes digestion and absorption, and eventually improves the overall performance of the bird (Tactacan et al., 2013; Latorre et al., 2014). However, little is available in the literature about the influence of $B$. subtilis QST-713 strain on the gut microarchitecture of broilers reared under controlled environment. Modulation of gut mucosal morphology is assumed to improve health indicators and production performance in birds (Awad et al., 2009). The gut mucosal barrier, which is consists of the epithelial cell membrane, which confers selective permeability and permits the entry of valuable molecules of available nutrients, also inhibits detrimental ingredients, including pathogenic bacteria and their toxins (Lee et al., 2015). Injury to the gut mucosal cells may provide chances for the entrance of injurious constituents, which may result in shortening of the villi and sloughing of the mucosal lining (Sikandar et al., 2017). The villi and microvilli increase the surface area for more efficient absorption of available nutrients in small intestine (Awad et al., 2009). The authors found increased VH, VSA, and villus to crypt ratio in B. subtilis-supplemented chickens (Table 7 and 8 ).

So, from this study, the authors can assume that absorptive function is increased in the modulated gut mucosa, which results in better performance in $B$. subtilis-supplemented groups compared with the control, similar to the findings of Al-Fataftah and Abdelqader (2014). Overall, lower villi heights were observed in the control group which may be linked with poor growth performance in that group.

Growing chickens rely on DFM to enhance immune system development and increase immune potential to resist infections (Lee et al., 2015). B. subtilis-type probiotic may stimulate subsets of immune cells to fabricate cytokines and antioxidants, which plays a role in the regulation of humoral and cellmediated immune responses. In higher concentration these results were even better than those of the $\mathrm{ZnB}$ and control group chickens.

\section{Conclusion}

Feed supplemented with $B$. subtilis QST-713 has a positive effect on animal performance and health status through development of the microarchitecture of the gut and immune organs. These modulations have a connection with improved growth and immunity, which suggests that they may be used as alternatives to synthetic AGP in healthy broiler chickens. Further analyses are needed to reveal the mechanism(s) by which B. subtilis produces such effects.

\section{Acknowledgments}

This project was supported by Higher Education Commission, Pakistan (HEC Project No. 2av1-147). The authors would also like to thank Prof. Dr. Ashiq Hussain Cheema for his guidance in the manuscript preparation.

\section{Authors' Contributions}

All authors contributed equally and read the final version of the manuscript. MY,SM and HR contributed to experimental design and data analysis. AA and MS performed immunology, while AS and HZ performed the microarchitectural analysis and wrote the manuscript.

\section{Conflict of Interest Declaration}

The authors have no conflict of interest to declare.

\section{References}

Al-Fataftah, A.R. \& Abdelqader, A., 2014. Effects of dietary Bacillus subtilis on heat-stressed broilers performance, intestinal morphology and microflora composition. Anim. Feed Sci. Technol. 198, 279-285.

Awad, W.A., Ghareeb, K., Abdel-Raheem, S. \& Bohm, J., 2009. Effects of dietary inclusion of probiotic and synbiotic on growth performance, organ weights, and intestinal histomorphology of broiler chickens. Poult. Sci. 88, 49-55.

Bancroft, J.D., Gamble, M. \& Bancroft, O.D., 2008. Theory and practice of histological techniques. 6th ed. Elsevier Health Sciences, NY. 725p.

Corrier, D.E., 1990. Comparison of phytohemagglutinin-induced cutaneous hypersensitivity reactions in the interdigital skin of broiler and layer chicks. Avian. Dis. 34, 369-373.

Dobson, A., Cotter, P.D., Ross, R.P. \& Hill, C., 2012. Bacteriocin production: a probiotic trait? Appl. Environ. Microbiol. 78, 1-6.

EFSA FEEDAP Panel (EFSA Panel on Additives and Products or Substances used in Animal Feed). 2015. Scientific opinion on the safety and efficacy of Bacillus subtilis PB6 (Bacillus subtilis) as a feed additive for laying hens and minor poultry species for laying. EFSA J. 13, 3970. 
Haghighi, H.R., Gong, J., Gyles, C.L, Hayes, M.A., Zhou, H., Sanei, B., Chambers, J.R. \& Sharif, S., 2006. Probiotics stimulate production of natural antibodies in chickens. Clin. Vaccine. Immunol. 13: 975-980.

Jiang, H.Q., Thurnheer, M.C., Zuercher, A.W., Boiko, N.V., Bos, N.A. \& Cebra, J.J., 2004. Interactions of commensal gut microbes with subsets of B- and T-cells in the murine host. Vaccine 22, 805-811.

Kabploy, K., Bunyapraphatsara, N., Morales, N.P. \& Paraksa, N., 2016. Effect of antibiotic growth promoters on antioxidative and anti-inflammatory activities in broiler chickens. Thai. J. Vet. Med. 46, 89-95.

Kiczorowska, B., Al-Yasiry, A.R.M., Samolińska, W., Marek, A. \& Pyzik, E., 2016. The effect of dietary supplementation of the broiler chicken diet with Boswellia serrata resin on growth performance, digestibility, and gastrointestinal characteristics, morphology, and microbiota. Livest. Sci. 191, 117-124.

Kundu, A., Singh, D.P., Mohapatra, S.C., Dash, B.B., Moudgal, R.P. \& Bisht, G.S., 1999. Antibody response to sheep erythrocytes in Indian native vis-`a-vis imported breeds of chickens. Brit. Poult. Sci. 40, 40-43.

Latorre, J.D., Hernandez-Velasco, X., Kallapura, G., Menconi, A., Pumford, N.R., Morgan, M.J., Layton, S.L., Bielke, L.R., Hargis, B.M. \& Tellez, G., 2014. Evaluation of germination, distribution, and persistence of Bacillus subtilis spores through the gastrointestinal tract of chickens. Poult. Sci. 93, 1-8.

Lee, K.W. \& Lillehoj, H.S., 2016. An update on direct-fed microbials in broiler chickens in post-antibiotic era. Anim. Prod. Sci. https://doi.org/10.1071/AN15666.

Lee, K.W., Kim, D.K., Lillehoj, H.S., Jang, S.I. \& Lee, S,H., 2015. Immune modulation by Bacillus subtilis-based direct-fed microbials in commercial broiler chickens. Anim. Feed. Sci. Technol. 200, 76-85.

Lei, X., Piao, X, Ru, Y., Zhang, H., Peron, A. \& Zhang, H., 2015. Effect of Bacillus amyloliquefaciens-based direct-fed microbial on performance, nutrient utilization, intestinal morphology and cecal microflora in broiler chickens. Asian-Australas. J. Anim. Sci. 28, 239-246.

Madej, J.P., Stefaniak, T. \& Bednarczyk, M., 2015. Effect of in ovo delivered prebiotics and synbiotics on lymphoid organs' morphology in chickens. Poult. Sci. 94, 1209-1219.

Molnar, R.A.K., Podmaniczky, B., Kurti, P., Tenk, I., Glavits, R., Virag, Gy. \& Szabo, Z.S., 2011. Effect of different concentrations of Bacillus subtilis on growth performance, carcase quality, gut microflora and immune response of broiler chickens. Brit. Poult. Sci. 52, 658-665.

Park, J.H. \& Kim, I.H., 2014. The effects of the supplementation of Bacillus subtilis RX7 and B2A strains on the performance, blood profiles, intestinal Salmonella concentration, noxious gas emission, organ weight and breast meat quality of broiler challenged with Salmonella typhimurium. J. Anim. Phy. Anim. Nutr. 99, 326-34.

Patel, S., Shukla, R. \& Goyal, A., 2015. Probiotics in valorization of innate immunity across various animal models. J. Funct. Foods. 14, 549-561.

Ragaa, N.M. \& Korany, R.M.S., 2016. Studying the effect of formic acid and potassium diformate on performance, immunity and gut health of broiler chickens. Anim. Nutr. 00, 1-7.

Rooney, A.A., Bermudez, D.S. \& Guillette, L.J., 2003. Altered histology of the thymus and spleen in contaminantexposed juvenile American alligators. J. Morphol. 256, 349-359.

Schwartzman, J.A. \& Edward, G. Ruby., 2016. Stress as a normal cue in the symbiotic environment. Trends Microbiol. 24, 414-424.

Sikandar, A., Zaneb, H., Younus, M., Khattak, F., Masood, S., Aslam, A., Ashraf, S., Rehman, H. \& Yousaf, M.S., 2017. Effect of sodium butyrate on performance, immune status, microarchitecture of small intestinal mucosa and lymphoid organs in broiler chickens. Asian-Australas. J. Anim. Sci. 13. doi: 10.5713/ajas.16.0824.

Slawinska, A., Siwek, M., Zylinska, J., Bardowski, J., Brzezinska, J., Gulewicz, K.A., Nowak, M., Urbanowski, M., Plowiec, A., Bednarczyk, M., 2014. Influence of synbiotics delivered in ovo on immune organ development and structure. Folia. Biologica. (Krakow) 62, 277-285.

Tactacan, G.B., Schmidt, J.K., Mille, M.J., Jimenez, D.R., 2013. A Bacillus subtilis (QST 713) spore-based probiotic for necrotic enteritis control in broiler chickens. J. Appl. Poult. Res. 22, 825-831.

Teo, A.Y., Tan, H.M., 2007. Evaluation of the performance and intestinal gut microflora of broilers fed on corn-soy diets supplemented with Bacillus subtilis PB6 (CloSTAT). J. Appl. Poult. Res. 16, 296-303.

Zhang, Z.F., Zhou, T.X., Ao, X. \& Kim, I.H., 2012. Effects of beta-glucan and Bacillus subtilis on growth performance, blood profiles, relative organ weight and meat quality in broilers fed maize-soybean meal based diets. Livestock Sci. 150, 419-424. 